DOI 10.37882/2500-3682.2021.03.07

\title{
ОСОБЕННОСТИ ПЕРЕЖИВАНИЯ СТРЕССА, ПСИХОЛОГИЧЕСКИХ ЗАЩИТ И КОПИНГ-СТРАТЕГИЙ У МОЛОДЕЖИ, ВЫЗВАННЫХ УГРОЗОЙ ЗАБОЛЕВАНИЯ COVID-19
}

\section{FEATURES OF STRESS, PSYCHOLOGICAL DEFENSE MECHANISMS AND COPING STRATEGIES IN YOUTH CAUSED BY THE THREAT OF COVID-19 DISEASE}

A. Kostrigin

Summary: The authors address the problem of stress caused by the threat of COVID-19 disease. It is noted that the various consequences of the coronavirus pandemic are reflected on the mental state of people, causing negative emotions and stress. The article presents the results of a study of the peculiarities of experiencing stress, psychological defense mechanisms and coping strategies in Russian youth caused by the threat of COVID-19 disease. The methods are "Diagnostics of typologies of psychological defense mechanisms" (Life Style Index; R. Plutchik in adaptation of L.I. Wasserman, 0. Eryshev, EB Klubova), "Coping behavior in stressful situations" (S. Norman, D.F. Endler, D.A. James, M.I. Parker; adapted version by T.A. Kryukova), "COVID Stress Scales" (S. Taylor, K. Landry, J. Asmudson and others; in the author's translation). It has been estimated that half of young people experience stress from COVID-19. It was found that the most significant factors causing stress are the very danger of infection, social-economic consequences and the fear of foreigners as a source of the disease (xenophobia). The most pronounced psychological defense mechanisms (projection and regression) and coping strategies (focused on emotions) in young people were revealed, aimed at reducing negative emotions and stress.

Keywords: stress, coronavirus, coping strategies, psychological protection, youth.

\section{Костригин Артем Андреевич}

К.nсх.н., старший преподаватель, Российский государственный университет им. А.Н. Косыгина

(Технологии. Дизайн. Искусство), Москва artdzen@gmail.com

Козлова Лидия Владимировна

Российский государственный университет им. А.Н. Косыгина (Технологии. Дизайн. Искусство), Москва lidiakozlova@bk.ru

Аннотация: В статье авторы обращаются к проблеме стресса, вызванного угрозой заболевания COVID-19. Отмечается, что различные последствия пандемии коронавируса отражаются на психическом состоянии людей, вызывая негативные эмоции и стресс. Представляются результаты исследования особенностей переживания стресса, психологических защит и копинг-стратегий у российской молодежи, вызванных угрозой заболевания COVID-19. Используются методики «Диагностика типологий психологической защиты» (Р. Плутчик в адаптации Л.И. Вассермана, О.Ф. Ерышева, Е.Б. Клубовой и др.), «Копинг-поведение в стрессовых ситуациях» (С. Норман, Д.Ф. Эндлер, Д.А. Джеймс, М.И. Паркер; адаптированный вариант Т.А. Крюковой), «Шкала стресса от COVID-19» (C. Тэйлор, К. Лэндри, Дж. Асмудсон и др.; в авторском переводе). Установлено, что половина молодых людей испытывает стресс от COVID-19. Обнаружено, что наиболее значимыми факторами, вызывающими стресс, являются сама опасность заражения, социально-экономические последствия и боязнь иностранцев как источника заболевания (ксенофобия). Выявлены наиболее выраженные психологические защиты (проекция и регрессия) и копинг-стратегии (ориентированные на эмоции) у молодежи, направленные на снижение негативных эмоций и стресса.

Ключевые слова: стресс, коронавирус, копинг-стратегии, психологическая защита, молодежь.

Данная проблема является актуальной, т.к. изменились условия жизни, трудовой деятельности и межличностного взаимодействия людей из-за эпидемиологической ситуации, что влечет за собой эмоциональные реакции и стресс. Рассмотрим зарубежные и российские работы, посвященные эмоциональным и стрессовым реакциям, вызванным пандемией коронавируса.

В связи с быстротой распространения вируса и развития эпидемии большинство авторов основывается на литературных источниках Китая или теоретических моделях, разработанных в прошлые пандемии [7]. Например, иранские исследователи А. Зандифар и Р. Бадрфам, подчеркивают роль непредсказуемости, неопределенности и неизвестности о серьезности заболевания, 
дезинформации в СМИ, социальной изоляции в утяжелении имеющегося стресса и увеличении количества психических расстройств в обществе [19]. Авторы убеждены в необходимости участия психиатрических служб в период социальной изоляции. Наряду с этим ученые из Японии отмечают воздействие COVID-19 на экономическое благосостояние населения, нарастание уровня страха и панического поведения [17]. К.Л. Парк с коллегами обнаружили стресс у американской выборки, связанный со страхом заболевания коронавирусом и финансовыми проблемами [16].

Российские авторы обнаружили сходные результаты и расширяют проблематику исследований. Т.А. Соколовская и Е.В. Бахадова изучали личностную и ситуативную тревожности, уровень самоактуализации российского населения в период самоизоляции при коронавирусе [8]. Были выявлены поведенческие и когнитивные реакции населения на ситуацию самоизоляции в виде стратегий наблюдения, невключенности или отключения себя от проблематики (характерно для людей в возрасте 1825 лет) и аналитического подхода к ситуации и высокой поисковой активности с концентрацией на «бытийные ответы» и «заботе о других» (характерно для людей 4565 лет).

М.Ю. Сорокин, Е.Д. Касьянов, Г.В. Рукавишников и др. изучали психологические реакции населения, связанные с распространением пандемии COVID-19, и предположили, что они специфически ассоциированы с поведением в процессе противоэпидемических мероприятий, что адаптивное поведение населения в период пандемии связано с социально-психологическими факторами [11]. По результатам проведенного исследования были выявлены взаимосвязи между уровнем психологического стресса и соблюдением режима самоизоляции, использованием социального дистанцирования, применением антисептиков, а также просмотром новостей о COVID-19 более одного раза в день. Также отмечались волнения по поводу отсутствия специфического лечения COVID-19, опасности для собственной жизни, заразности вируса и дефицита средств защиты, которые соотносятся авторами с формированием защитного поведения, связанного с гигиеной рук (положительная корреляция) и ношением маски (отрицательная корреляция). Самым распространенным типом переживаний по результатам опроса является страх за близких. Таким образом, самоизоляция, социальное дистанцирование и обилие разнородной информации в CMИ о COVID-19 признаны авторами реальными стрессовыми факторами для русскоязычного населения.

Наряду с опросами населения, нам представляются интересными результаты двух экспертных опросов российских психологов-исследователей и психологовпрактиков, посвященных социально-психологическим аспектам пандемии COVID-19. Авторы подчеркивают, что «экспертным» этот опрос можно считать только условно, т.к. по данной проблеме нет экспертов ввиду новизны угрозы. Анализируя ответы на закрытые и открытые вопросы в первой и второй волнах анкетирования, они приходят к выводу, что психологи-исследователи и психологи-практики сходятся в оценке последствий пандемии, а также в представлениях о мерах, которые необходимы для их преодоления. В целом экспертная позиция российских психологов вполне соответствует результатам отечественных и зарубежных эмпирических и др. Они считают, что вклад в развитие этого направления сможет внести междисциплинарное математическое моделирование социальных и психологических последствий пандемий, а также анализ цифровых следов [13].

Во втором опросе, проведенном этими же авторами, опрошенные психологи считают, что маловероятно развитие сценариев с полной победой человечества над вирусом и победой вируса над человечеством. Более реальным эксперты считают промежуточный сценарий: человечество свыкается со смертностью от коронавируса и практически перестанет ее замечать. Психологи прогнозируют привыкание, а также отмечают многие положительные черты режима самоизоляции. Участники опроса указывают на необоснованность объяснений, которые дает власть своим действиям, и систематическое расхождение их с мнением экспертного сообщества, но в целом, несмотря на это, участники опроса поддерживают действия властей по сдерживанию эпидемии. Перспектива видения ситуации экспертами несколько шире, чем у представителей власти, принимающей решения относительно пандемии. Таким образом, обращение к жанру экспертных опросов оправдано и позволяет получить информацию об эпидемии, не получаемую посредством традиционных опросов [14].

Проведенный теоретический анализ показывает, что эмоциональные и стрессовые реакции людей, вызванные пандемией COVID-19, являются актуальным направлением исследований. Однако стоит методологическая проблема определения стресса, специфического для COVID-19. В зарубежной литературе, кроме собственно исследований и экспертной аналитики по проблемам влияния пандемии COVID-19 на психическое состояние людей, активно разрабатываются методы диагностики стресса, вызванного угрозой заражения COVID-19 [15; 16]. Российские исследователи используют методики, диагностирующие либо общее состояние стресса, либо связанные со стрессом состояния (эмоции, тревога и др.) $[4 ; 8 ; 9 ; 12]$.

Данное исследование ставит цель изучения стресса, вызванного угрозой заражения COVID-19, с помощью опросника, разработанного С. Тэйлором и его коллегами [18]. Новизной нашей работы является перевод и применение данной методики на российской выборке, а также изучение именно российской молодежи. 


\section{Материалы и методы}

Данное исследование было проведено в ноябре 2020 г. - в период «второй волны» COVID-19 в России $[3,4,10]$. Актуальность изучения особенностей стрессовых реакций и копинг-стратегий, проявляемых на фоне стресса от пандемии, была обоснована необходимостью оказания в будущем правильной и необходимой психологической помощи людям, подверженным сильному стрессу от пандемии $[1 ; 6 ; 9 ; 11]$.

Цель исследования - изучение особенностей стрессовых реакций, психологических защит и копинг-стратегий у молодежи, вызванных угрозой заражения COVID-19.

Выборка - 102 человека в возрасте от 17 до 26 лет, среди которых 63,7\% испытуемых женского пола, 36,3\% испытуемых мужского пола. Средний возраст выборки 19,3 лет. В качестве методов исследования были выбраны методики «Диагностика типологий психологической защиты» (Р. Плутчик в адаптации Л.И. Вассермана, О.Ф. Ерышева, Е.Б. Клубовой и др.), «Копинг-поведение в стрессовых ситуациях» (С. Норман, Д.Ф. Эндлер, Д.А. Джеймс, М.И. Паркер; адаптированный вариант Т.А.Крюковой), «Шкала стресса от COVID-19» (COVID Stress Scales) (C. Тэйлор, К. Лэндри, Дж. Асмудсон и др.; в авторском переводе) [18]. Обработка данных проводилась с помощью статистического критерия U Манна-Уитни.

Методика «Шкала стресса от COVID-19» была переведена и адаптирована для русскоязычного населения [2]. Данная методика включает в себя такие шкалы, как «Опасность», «Социально-экономические последствия», «Ксенофобия», «Заражение», «Травматический стресс» и «Контроль».

\section{Результаты исследования}

Было установлено, что половина российской молодежи (51 человек; 50\%) переживает стресс от угрозы заболевания COVID-19. Далее выборка была разделена на две подгруппы с высоким (51 человек) и низким (51 человек) уровнем стресса от COVID-19. Разделение на подгруппы было основано на шкале «Опасность» по методике «Шкала стресса от COVID-19», т.к. данная шкала определяет общее отношение и общее стрессовое состояние в условиях пандемии.

При сравнении двух групп молодежи с высоким и низким уровнем стресса были выявлены значимые различия (см. таблицу). Молодые люди с высоким уровнем стресса, вызванного угрозой заражения COVID-19, обладают более высокими показателями уровня стресса по шкалам «Социально-экономические последствия», «Ксенофобия», «Заражение», чем группа молодежи с низким уровнем стресса. Это означает, что молодежь, переживающая стресс в связи с угрозой COVID-19, намного больше беспокоится о последствиях заражения вирусом и социально-экономических последствиях, на фоне чего развивается и ксенофобия, выражающаяся в виде боязни иностранцев как потенциального источника заражения. Группа с низким уровнем стресса подвержена данным факторам в значительно меньшей степени.

Таблица

Особенности переживания стресса, психологических защит и копинг-стратегий у молодежи

\begin{tabular}{|l|c|c|c|}
\multicolumn{1}{|c|}{ Показатели } & $\begin{array}{c}\text { Молодежь с } \\
\text { высоким уров- } \\
\text { нем стресса, } \\
\text { вызванного } \\
\text { опасностью } \\
\text { СоVID-19 }\end{array}$ & $\begin{array}{c}\text { Молодежь с } \\
\text { низким уров- } \\
\text { нем стресса, } \\
\text { вызванного } \\
\text { опасностью } \\
\text { COVID-19 }\end{array}$ & $\begin{array}{c}\text { уночимень } \\
\text { различий, P }\end{array}$ \\
\hline Опасность & 15,6 & 7,4 & 0,000000 \\
\hline $\begin{array}{l}\text { Социально-экономи- } \\
\text { ческие последствия }\end{array}$ & 3,9 & 2,08 & 0,000604 \\
\hline Ксенофобия & 2,7 & 1,4 & 0,048343 \\
\hline Заражение & 6,5 & 2,9 & 0,000003 \\
\hline Регрессия & 6,51 & 4,8 & 0,028149 \\
\hline Проекция & 45,1 & 39,9 & 0,000174 \\
\hline Эмоции & & & 0,023897 \\
\hline
\end{tabular}

Также были обнаружены значимые различия по типам психологических защит и копинг-стратегий, используемых молодежью для совладания со стрессом, вызванного угрозой заражения COVID-19. Группа молодых людей с ярко выраженным стрессом наиболее часто использует для совладания такие психологические защиты, как «проекция» и «регрессия». Молодежь, подверженная стрессу, склонна проецировать свои переживания, вызванные опасностью коронавируса, на других, не желая демонстрировать и проявлять их. Также группа, подверженная стрессу, чаще использует механизм психологической защиты «регрессия», поэтому отличается значительной импульсивностью и слабостью эмоционально-волевого контроля. Такая молодежь более склонна к изменению эмоциональной сферы в сторону большей упрощенности, заменяет решение субъективно более сложных задач относительно более простыми и доступными в сложившейся ситуации стресса. Вторая группа, не подверженная стрессу в связи с угрозой COVID-19, предпочитает использовать другие типы психологической защиты.

Кроме этого, обнаружено различие в использовании копинг-стратегии «эмоции» у групп молодежи с разной выраженностью стресса, вызванного угрозой заражения COVID-19. Молодые люди с высоким уровнем стресса реагируют эмоционально в большей степени, испытывают эмоции различного спектра и нуждаются в психологической разрядке. 


\section{Выво $\Delta ы$}

Проведенное исследование выявило особенности переживания стресса у молодежи, вызванного угрозой заражения COVID-19.

1. Установлено, что половина молодых людей испытывает стресс от COVID-19, что показывает значимость самой пандемии и ее социально-экономических и психологических последствий для российской молодежи.

2. Обнаружено, что наиболее значимыми факторами, вызывающими стресс, являются сама опасность заражения, социально-экономические последствия и боязнь иностранцев как источника заболевания (ксенофобия). Данные факторы от- носятся к внешней сфере жизнедеятельности молодежи. Молодые люди не переживают стресс, связанный с психологическим состоянием и повседневной деятельностью, а значит в этих сферах самоконтроль у них не снижен.

3. Выявлены наиболее выраженные психологические защиты (проекция и регрессия) и копингстратегии (ориентированные на эмоции) у молодежи, направленные на снижение негативных эмоций и стресса, вызванных COVID-19. Российская молодежь справляется со стрессом с помощью изменения эмоциональных реакций; их эмоциональное поведение становится более выраженным, упрощается и направляется на окружающие объекты и людей.

\section{ЛИТЕРАТУРА}

1. Калинина Н.В., Дмитриева Ю.Н., Володина Т.В. Жизнестойкость как ресурс преодоления трудных жизненных ситуаций. - Ульяновск: УИПКПРО, 2012. 183 c.

2. Козлова Л.В., Костригин А.А. Стресс, вызванный угрозой заражения коронавирусом, и преобладающие копинг-стратегии у молодежи // Вестник по педагогике и психологии Южной Сибири. - 2020. - № 4. - С. 33-48.

3. Костенко Я., Сидоренко Е. Ушел в глубинку: вторая волна коронавируса накрывает регионы [Электронный ресурс] // Известия. - 2020. - 25 ноября. URL: https://iz.ru/1092061/iaroslava-kostenko-elena-sidorenko/ushel-v-glubinku-vtoraia-volna-koronavirusa-nakryvaet-regiony

4. Крюкова Т.Л., Екимчик 0.А., Опекина Т.П., Шипова Н.С. Стресс и совладание в семье в период самоизоляции во время пандемии COVID-19 // Социальная психология и общество. - 2020. - Т. 11. - № 4. - С. 120-134.

5. На Москву и Петербург приходится 40\% новых заболевших COVID-19 [Электронный ресурс] // РИА Новости. - 2020. - 1 декабря. URL: https://ria.ru/20201201/koronavirus-1587158567.html

6. Нестик T.A. Влияние пандемии COVID-19 на общество: социально-психологический анализ // Институт психологии Российской академии наук. Социальная и экономическая психология. - 2020. - Т. 5. - № 2 (18). - С. 47-83.

7. Островский Д.И., Иванова Т.И. Влияние новой коронавирусной инфекции COVID-19 на психическое здоровье человека (0бзор литературы) // Омский психиатрический журнал. - 2020. - № 2-S1 (24). - С. 4-10.

8. Соколовская Т.А., Бахадова Е.В. Тревожность и самоактуализация личности как эмоциональный когнитивный и поведенческий ответ на самоизоляцию в период COVID-19: новые вызовы для общественного здоровья // Научное обозрение. Медицинские науки. - 2020. - № 3. - C. 64-70.

9. Соловьева Н.В., Макарова Е.В., Кичук И.В. «Коронавирусный синдром»: профилактика психотравмы, вызванной COVID-19 // PMЖ. - 2020. - T. 28. № 9. - C. 18-22.

10. Соловьева 0. Вторая волна коронавируса опрокидывает надежды на быстрое оживление [Электронный ресурс] // Независимая газета. - 2020. 15 ноября. - URL: https://www.ng.ru/economics/2020-11-15/4_8014_wave.html

11. Сорокин М.Ю., Касьянов Е.Д., Рукавишников Г.В., Макаревич О.В., Незнанов Н.Г., Лутова Н.Б., Мазо Г.Э. Психологические реакции населения как фактор адаптации к пандемии COVID-19 // Обозрение психиатрии и медицинской психологии имени В.М. Бехтерева. - 2020. - № 2. - C. 87-94.

12. Тепанян С.А. Влияние пандемии COVID-19 на психологическое состояние населения // Научно-практические исследования. - 2020. - № 12-2 (35). C. 63-70.

13. Ушаков Д.В., Юревич А.В., Нестик Т.А., Юревич М.А. Социально-психологические аспекты пандемии COVID-19: результаты экспертного опроса российских психологов // Психологический журнал. - 2020. - Т. 41. - № 5. - С. 5-17.

14. Юревич А.В., Ушаков Д.В., Юревич М.А. СОVID-19: результаты второго экспертного опроса // Психологический журнал. - 2020. - Т. 41. - № 6. - С. 78-85.

15. Islam S.M.D.-U. et al. Exploring COVID-19 stress and its factors in Bangladesh: a perception-based study // Heliyon. - 2020. - Vol. 6. - № 7. - P. e04399.

16. Park C.L. et al. Americans' COVID-19 stress, coping, and adherence to CDC guidelines // Journal of general internal medicine. - 2020. - Vol. 35. - № 8. - P. 22962303.

17. Shigemura J. et al. Public responses to the novel 2019 coronavirus (2019-nCoV) in Japan: Mental health consequences and target populations // Psychiatry and clinical neurosciences. - 2020. - Vol. 74. - № 4. - P. 281-282.

18. Taylor S. et al. Development and initial validation of the COVID Stress Scales // Journal of anxiety disorders. - 2020. - Vol. 72. - URL: http://www.sciencedirect. com/science/article/pii/S0887618520300463

19. Zandifar A., Badrfam R. Iranian mental health during the COVID-19 epidemic // Asian journal of psychiatry. - 2020. - Vol. 51. - URL: https://www.sciencedirect. com/science/article/abs/pii/S1876201820300988 